\title{
Verisimilitude (or "truthlikeness") as an alternative to pro and cons: migraine and cluster headache mechanisms
}

\author{
Peer Carsten Tfelt-Hansen
}

Received: 11 May 2010/ Accepted: 4 June 2010/Published online: 7 July 2010

(C) Springer-Verlag 2010

\begin{abstract}
Calculating verisimilitude (or "truthlikeness") ad modum Popper is a quantitative alternative to the usual pros and cons in migraine and cluster headache mechanisms. The following items were evaluated: dilation of large cranial arteries during migraine; CGRP increase during migraine; migraine as a brain disorder; aura and migraine headache; brain stem activation during migraine; rCBF in migraine without aura; NO and pathophysiology of migraine; neurogenic inflammation and migraine; aura in cluster headache; and hypothalamic activation in cluster headache. It is concluded that verisimilitude calculations can be helpful when judging pathophysiological problems in migraine and cluster headache.
\end{abstract}

Keywords Migraine Cluster headache .

Pathophysiology · Mechanism · Verisimilitude

What Hume called our 'natural instincts' are stronger than any philosophical argument. In my view this applies to science as well.

Peter Lipton, 2005 [1].

\section{Introduction}

Pathophysiological studies of migraine often involve new techniques to reveal abnormalities compared with a control

P. C. Tfelt-Hansen $(\square)$

Department of Neurology, Danish Headache Centre,

Glostrup Hospital, University of Copenhagen,

Glostrup, Denmark

e-mail: ptha@glo.regionh.dk group. Alternatively, an intervention provokes a migraine attack [2-5], with patients assessed before and after the intervention. Migraine research is increasingly hypothesis driven as migraine mechanisms become better understood $[6,7]$.

Philosopher of science Sir Karl Popper stated, "a good theory...makes a number of predictions that can in principle be disproved or falsified by observation" [8]. Established methods for comparing drug effects [9] include designing randomized clinical trials based on the null hypothesis. Additionally, systematic reviews or metaanalyses can estimate effects within $95 \%$ confidence intervals (CI) [10-13]. Systematic meta-analyses are not applicable to migraine mechanism theories and differing results with different methodologies prevent direct comparisons. To deal with such situations, Popper introduced the concept of verisimilitude (or "truthlikeness") [14] to score the degree of likelihood of truth in a theory or statement. The concept has advantages over the pros and cons that are normally used where there are disagreements, as often occur in headache research. We applied the concept to several important migraine and cluster headache mechanisms. This exercise is aimed toward enlightening the migraine research field and to indicate where further research is needed.

\section{Methods}

Verisimilitude (or "truthlikeness") of a theory $a$ can be expressed ad modum Popper [14] as:

$\mathrm{Vs}(a)=\mathrm{CT}_{\mathrm{v}}(a)-\mathrm{CT}_{\mathrm{f}}(a)$

where $\operatorname{Vs}(a)$ is the verisimilitude of $a, \mathrm{CT}_{\mathrm{v}}(a)$ is a measure of the truth content of $a$, and $\mathrm{CT}_{\mathrm{f}}(a)$ is a measure of the falsity of $a$ [14]. 
When calculating $\operatorname{Vs}(a)$ in Table 1 , both $\operatorname{CT}_{\mathrm{v}}(a)$ and $\mathrm{CT}_{\mathrm{f}}(a)$ were given arbitrary values of $0,0.25,0.5,0.75$, or 1.0 for simplicity. The results for verisimilitude, $\mathrm{Vs}(a)$, can thus be -1.0 (very unlikely), -0.75 (most unlikely), -0.5 (unlikely), -0.25 (probably unlikely), 0 (undecided), +0.25 (probably likely), +0.5 (likely), +0.75 (most likely), or +1.0 (very likely).

To exemplify, we chose both easy problems and problems requiring extensive comments and where the result of the analyses remains open for discussion. Our judgment of the evidence, indicated as $\mathrm{CT}_{\mathrm{v}}(a)$ and $\mathrm{CT}_{\mathrm{f}}(a)$, is given in Table 1 together with the calculated $\operatorname{Vs}(a)$.

\section{Results and comments}

Does dilation of larger cranial arteries cause the pain in migraine headache?

Extracranial arterial vasodilation is traditionally regarded as the cause of migraine headache [15, 16]. Increased temporal pulsations were observed during migraine, and these pulsations decreased after intravenous ergotamine in parallel with the effect on headache [15]. Decreased blood velocity in the middle cerebral artery (MCA) during migraine, measured with transcranial Doppler (TCD), was found [17]. Since the cerebral blood flow was unchanged, it indicated dilation of the MCA [17]. This finding was confirmed with TCD in two small studies in 25 [18] and 10 [19] patients, respectively. The $\operatorname{CT}_{\mathrm{v}}(a)$ is 1.0 .

In two relatively large studies with 31 [20] and 51 [21] patients, respectively, no decrease in blood flow velocity was found with TCD during migraine attacks. Furthermore, a recent magnetic resonance angiography (MRA) study found no MCA or extracranial part of the middle meningeal artery (MMA) dilatation during nitroglycerin-induced migraine $(n=20)$ [22]. Arguably, a negative study could theoretically be caused by variability in measurements, but in the MRA study [22], MMA (17\%) and MCA (11\%) vasodilation was observed during the 20-min infusion of nitroglycerin. We judge the $\mathrm{CT}_{\mathrm{f}}(a)$ to be 1.0. The verdict is still out concerning large cranial artery vasodilatation during migraine and the verisimilitude is 0 .

Is calcitonin gene-related peptide (CGRP) increased in the external jugular vein (EJV) during migraine attacks?

For many years it has been known that CGRP is increased in the EJV blood during migraine attacks [23, 24] leading to the conclusion that CGRP is a neuropeptide elevated during migraine attacks [25]. In a study of very long- standing attacks (median $11 \mathrm{~h}$ ), sumatriptan treatment normalized CGRP levels [24]. The $\mathrm{CT}_{\mathrm{v}}(a)$ is 1.0.

Calcitonin gene-related peptide (CGRP) was unchanged in two spontaneous migraine studies [26, 27]. Both the studies used intra-patient design [26, 27]. In one study [26], two CGRP analyses methods were used including a method used previously by Goadsby et al. [23, 24], but no change in CGRP was observed. Furthermore, in one nitroglycerininduced migraine attack study, CGRP was not increased [27]. The $\mathrm{CT}_{\mathrm{f}}(a)$ is 1.0. Currently, there is similar evidence for and against increased CGRP in the EJV, and the verisimilitude is 0 .

Is migraine a dysfunction of the sensory modulatory network?

Most neurologists agree that migraine starts in the brain and confer the prodromes and aura, but their opinions about the headache phase differ. Recently, a proponent of pure CNS pathophysiology stated, "Migraine is a dysfunction of the sensory modulatory network with the dominant disturbance affecting abnormal processing of essentially normal neuronal traffic" [7].

The prodromes that occur in $30 \%$ of patients [28] and auras that occur in $20 \%$ of patients [29] must originate in the CNS. During aura, there is a characteristic spreading oligemia in the cerebral cortex [30-32]. Other evidence for CNS involvement during migraine attacks is available. Persistent brain stem activation was observed by PET during migraine attack [4, 33, 34]. Additionally, hypothalamic activation is observed during migraine attacks [34]. Few cases of symptomatic migraine caused by brain stem lesions are reported [35, 36]. Other migraine symptoms, such as photo- and phonophobia, are without peripheral cause [7]. $\beta$-blockers used as migraine prophylactics probably exert their effect in the CNS [37]. Valproate and topiramate also probably work in the CNS [29]. In rats, chronically administered prophylactic migraine drugs like propranolol, valproate, topiramate amitriptyline, and methysergide suppressed CSD frequency and increased the cathodal stimulation threshold required to evoke CSD [38].

Additionally, 5- $\mathrm{HT}_{1 \mathrm{~B} / 1 \mathrm{D}}$ receptors are present in the brain stem [39], which could explain the efficacy of triptans and alkaloids in migraine. There are many pros and the $\mathrm{CT}_{\mathrm{v}}(a)$ is 1.0 .

In an animal model of migraine, c-fos expression and the "evoked potential" are observed in the trigeminal nucleus caudalis (TNC) after superior sagittal sinus stimulation in the cat [40-43]. There appears to be a peripheral source for this "brain stem" activity in the animal migraine model. CSD activates trigeminal afferents, resulting in a series of cortical, meningeal, and brain stem events consistent with the development of a process similar to 
Table 1 Verisimilitude calculations for proposed migraine and cluster headache mechanisms (for details, see text)

Hypothesis (prediction)

\begin{tabular}{lcc}
\hline $\mathrm{Vs}(a)$ & $\mathrm{CT}_{\mathrm{v}}(a)$ & $\mathrm{CT}_{\mathrm{f}}(a)$ \\
\hline $\begin{array}{l}\text { Vasodilation of large cranial arteries is involved in migraine pain } \\
\text { Vasodilation of large arteries during }\end{array}$ & $\begin{array}{ll}\text { Increased temporal pulsations during migraine } \\
\text { migraine is undecided (0) }\end{array}$ & No change in MCA velocity measured with \\
& and the effect of ergotamine [15]. Decreased & TCD [20, 21] No vasodilatation measured \\
& blood velocity in MCA during migraine & directly with MCA in MMA and MCA during \\
& measured with TCD [17-19] (1.0) & NTG-induced migraine [22] (1.0)
\end{tabular}

Calcitonin gene-related peptide (CGRP) is increased in the external jugular vein (EJV) during migraine

CGRP increase in EJV during migraine CGRP was increased in EJV in two studies remains undecided $(0)$
$[23,24]$. In one study, sumatriptan treatment normalized CGRP levels [24] (1.0)
CGRP was unchanged in two studies on spontaneous migraine $[26,27]$ and one study in nitroglycerin-induced migraine [27] (1.0)

Migraine is a dysfunction of the sensory modulatory network with the dominant disturbance affecting abnormal processing of essentially normal neuronal traffic [7]

Whether a migraine attack is a pure neuronal A migraine attack must start in the brain to process without vascular components being involved is unresolved (0). See text cause the prodromes and aura. Persistent activation in the brain stem is observed by PET during migraine attack $[4,33]$. Few cases of symptomatic migraine are caused by brain stem lesions $[35,36]$. Other migraine symptoms, photo- and phonophobia, have no peripheral cause [7]. The $\beta$-blockers used in migraine prophylaxis probably exert their effect in the CNS [37]. Valproate and topiramate also most likely work in the CNS [29] (1.0)
Does aura trigger headache in migraine attacks?
Aura is likely to trigger a migraine attack $(+0.25)$
Clinically, the headache in migraine is contralateral to aura in $92 \%$ [58] Experimentally, CSD activates trigeminal afferents and evokes a series of cortical meningeal and brain stem events consistent with headache development in rats [44]. CSD activates matrix metalloproteinase, which opens the blood-brain barrier [62] (0.75)

Brain stem activation occurs during spontaneous and provoked migraine attacks
Brain stem most likely activated during migraine, but lateralization doubtful; pathophysiological implications somewhat unclear. $(+0.75)$
Two PET studies in spontaneous $[33,34]$ and one in NTG-induced migraine [4], showed brain stem activation which persisted after sumatriptan treatment $[4,33,34](1.0)$ enal cerebral blood flow (rCBF) is normal in migraine without aura

No firm conclusions $(0)$

rCBF measurements were normal in one SPECT study [68]. Brain stem activated in migraine but no occipital hypoperfusion observed by PET $[4,34]$. Normal rCBF measured with PWI [69] (1.0)
C-fos expression and "evoked potential" are observed in TNC after superior sagittal sinus stimulation in the cat model of migraine. [42]. There may be a peripheral source for activity. No other part of the body experiences pain without nociceptive input, except thalamic pain and other neuronal lesions with sensory sign [129]. A pure neuronal disorder does not explain the comorbidities of migraine with aura and stroke and ischemic heart disease [48, 49, 129]; a vascular or systemic factor must be involved. A central theory would not explain possible CGRP increases in EJV [23, 24]. Systemic endothelial dysfunction present in migraine [127] (1.0)

Clinically, there are well-documented cases of headache ipsilateral to aura [57]. Patients with aura but no headache challenge the notion that aura causes headache. [57]. Aura does not necessarily precede headache [57]. Experimentally, no correlation between CSD and neurogenic inflammation and nociception in rats. [66] $(0.5)$

Lateralization of activation and pain is inconsistent. In one study, PET activation was ipsilateral [4], in two others contralateral $[33,34]$ or bilateral [34] to pain $(0.25)$

Occipital hypoperfusion was observed with PET $(n=6)$ [73]. Spreading oligemia observed with PET in one case [74]. A SPECT study showed focal hypoperfusion in $74 \%$ of patients [70]. Patchy hypoperfusion was observed [71]. Small general reduction of $\mathrm{CBF}$ [72] (1.0)

NO is involved in migraine pathophysiology. iNOS inhibitors will be effective migraine prophylactics

NO is likely involved in migraine $(+0.5)$

Nitroglycerin induces genuine migraine attacks $[22,75-83]$. L-NMMA is effective in migraine [84] (1.0)
INOS inhibitors (GW273629, GW274150) were ineffective in treating migraine attacks $[85,86]$. GW274150 was ineffective as a prophylactic agent $[86,87](0.25)$ 
Table 1 continued

\begin{tabular}{|c|c|c|}
\hline \multicolumn{3}{|l|}{ Hypothesis (prediction) } \\
\hline $\mathrm{Vs}(a)$ & $\mathrm{CT}_{\mathrm{v}}(a)$ & $\mathrm{CT}_{\mathrm{f}}(a)$ \\
\hline \multicolumn{3}{|c|}{ Dural neurogenic inflammation (NI) is involved in migraine, predicting effectiveness of NI inhibitors in migraine } \\
\hline $\begin{array}{l}\text { NI unlikely to have a pivotal role in migraine } \\
\text { pain }(-0.5)\end{array}$ & $\begin{array}{l}\text { Endothelin and NK-1 receptor antagonists } \\
\text { effectively inhibit NI in animal studies } \\
{[94,95] \text {. In addition, triptans and ergot }} \\
\text { alkaloids inhibits NI }[90,91](0.5)\end{array}$ & $\begin{array}{l}\text { Randomized clinical trials show no effect of } \\
\text { substance P, neurokinin-1 antagonists } \\
\text { [96-98], neurosteroid ganaxolone [99], } \\
\text { endothelin antagonist [100], or specific NI } \\
\text { blockers [101, 102] (1.0) }\end{array}$ \\
\hline \multicolumn{3}{|c|}{ Aura is common in cluster headache patients [Schürks-et al-2006] ${ }^{\mathrm{a}}$} \\
\hline Aura must be rare in cluster headache $(-0.5)$ & $\begin{array}{l}\text { Aura occurred in } 4 \%[106], 14 \% \text { [103], } 23 \% \\
\text { [104], and } 28 \% \text { [105] of cluster headache } \\
\text { patients }(0.5)\end{array}$ & $\begin{array}{l}\text { None of } 554 \text { cluster headache patients } \\
\text { experienced aura [111] (1.0) }\end{array}$ \\
\hline \multicolumn{3}{|c|}{ Hypothalamic activation is specific for cluster headache and other trigeminal autonomic cephalalgia (TAC) [133] } \\
\hline $\begin{array}{l}\text { Hypothalamic activation is not cluster } \\
\text { headache specific; the Popper falsification } \\
\text { rule [8] was used }\end{array}$ & $\begin{array}{l}\text { Activation in the posterior hypothalamus } \\
\text { during nitroglycerin-induced cluster } \\
\text { headache attacks was observed by PET } \\
{[112,113] . \text { In migraine without aura, no }} \\
\text { hypothalamic activation was found in two } \\
\text { PET studies }[4,33] \text {. In two SUNCT patients, } \\
\text { functional MRI identified hypothalamic } \\
\text { activation }[116,117]\end{array}$ & $\begin{array}{l}\text { Activation was observed in both the } \\
\text { hypothalamus and brain stem }(n=7) \text { with } \\
\text { PET [34] }\end{array}$ \\
\hline
\end{tabular}

headache pain transmitted by the trigeminal nerve in this animal model of migraine with aura [44]. In another study, CSD directly activated trigeminovascular nociceptors without perivascular meningeal inflammation (the dura mater was not examined) [45].

If the carotid artery is occluded ipsilateral to the side of migraine headache then two-thirds will experience relief [46] indicating that cranial arteries are involved in migraine pain. The co-morbidities of migraine with aura and stroke, ischemic heart disease, and cervical arterial dissection [47$53]$ indicate a vascular or systemic component in migraine. The possible increased release of CGRP [23, 24, 54] in the external jugular vein is probably due to CGRP released locally from perivascular nerves. The small possible "infarcts" observed with MRI in the posterior cerebral circulation [55] indicate a vascular genesis. Brachial artery diameter (mean 4.82 vs. $5.39 \mathrm{~mm}$ ) and compliance (mean 0.30 vs. $0.37 \mathrm{~mm}^{2} / \mathrm{kPa}$ ) were decreased in migraine patients compared with controls [56]. Carotid arterial wall properties were similar between groups [56]. The $\mathrm{CT}_{\mathrm{f}}(a)$ was 1.0 and the verisimilitude was 0 .

Does aura trigger the headache in migraine attacks?

The relationship between aura and headache in migraine with aura has been questioned [57]. Some clinical evidence for a relationship exists. Thus, 35 (92\%, 95 CI: 79-98\%) out of 38 patients in whom both aura and headache were unilateral, felt that the headache and the aura were contralateral to each other; i.e. the headache was perceived over the affected hemisphere [58]. Aura and headache were perceived as ipsilateral only in 3 patients. Notably, the results were obtained with prospective-symptom recording. As much as 19 patients had bilateral headache and could not provide evidence on whether or not aura triggers headache [58].

Experimentally, CSD activates trigeminal afferents and evokes a series of cortical meningeal and brain stem events [44]. Several other animal studies showed that CSD can cause activation of the brain stem [59-61]. CSD activates matrix metalloproteinases, which open the blood-brain barrier [62]. In one study, activation of trigeminovascular nociceptors by CSD occurred without perivascular inflammation [45]. Neurogenic inflammation is, however, unlikely to be involved in migraine pain or in the link between aura and headache. Overall the $\mathrm{CT}_{\mathrm{v}}(a)$ is 1.0.

A clinical argument against aura as a migraine trigger is that most migraineurs never experience aura [29, 63], but the headache phase is, in principle, the same in migraine with or without aura [29]. Additionally, there are well-documented cases of headache ipsilateral to aura [57]. Patients with aura, but no headache are not uncommon [64, 65], challenging [57, 63 ] the notion that aura causes headache. Aura does not necessarily precede headache [57].

Experimental evidence against aura as a trigger of migraine pain comes from two studies in which there was no activation or sensitization of second-order neurons in TNC by CSD [66, 67]. The $\mathrm{CT}_{\mathrm{f}}(a)$ is 0.5 .

I believe aura is likely to trigger a migraine attack, and the verisimilitude is +0.5 . 
Is brain stem activation measured with PET present during migraine attacks?

In three PET studies, brain stem activation was observed $[4,33,34]$. This activation persisted after treatment with sumatriptan [4, 33, 34]. Therefore, in all PET studies conducted so far, brain stem activation was found and the $\mathrm{CT}_{\mathrm{v}}(a)$ is 1.0. However, there is an unexplained inconsistency concerning the lateralization of activation and pain. In one study, PET activation was ipsilateral to pain [4], whereas it was contralateral $[33,34]$ or bilateral [34] to pain in others. The $\mathrm{CT}_{\mathrm{f}}(a)$ is 0.25 . Brain stem activation during migraine is probable. However, lateralization is doubtful, making the pathophysiological implications unclear and the final verisimilitude is +0.75 .

Is regional cerebral blood flow (rCBF) normal during attacks of migraine without aura?

rCBF, measured with SPECT, was normal before and during 8 wine-induced migraines without aura attacks [68]. In two PET studies in migraine without aura attacks in either spontaneous $(n=9)$ [33] or GTN-induced $(n=24)$ [4] attacks, there was no occipital hypoperfusion. During spontaneous migraine attacks with a duration of 1-11 h, perfusion-weighted imaging reveals normal hemodynamic $(n=13)$ [69]. The $\mathrm{CT}_{\mathrm{v}}(a)$ is judged to be 1.0 .

rCBF during spontaneous/induced migraine without aura attacks were investigated with SPECT $(n=35)$ [70] and $74 \%$ of patients displayed an unilateral hypoperfusion, mainly in the occipital region. In one PET study, there was generally no change in $\mathrm{rCBF}$, but analysis of individual data showed patchy hypoperfusion in the temporo/occipital region in 4 patients with migraine without aura [71]. Global CBF was slightly, but significantly reduced in migraine without aura attacks compared with outside attacks $(n=9), 53$ versus $60 \mathrm{ml} / \mathrm{min} / 100 \mathrm{~g}$, respectively [72]. Occipital hypoperfusion was observed in another PET investigation in established attacks without aura $(n=6)$ [73]. Spreading oligemia was observed with PET in one case [74]. The resulting $\mathrm{CT}_{\mathrm{f}}(a)$ is most likely 1.0. Thus, no firm conclusion concerning $\mathrm{rCBF}$ in migraine without aura can presently be drawn and the verisimilitude is 0 .

Is NO involved in migraine pathophysiology?

Glyceryl trinitrate induced migraine without aura with a latency of some hours in migraine sufferers, with and without aura, in 11 studies [2, 22, 75-83]. A double-blind, placebo-controlled design was used in two investigations $[22,78]$. The NOS inhibitor, L-NMMA effectively treated migraine attacks [84]. The $\mathrm{CT}_{\mathrm{v}}(a)$ is 1.0 .
However, the two iNOS inhibitors GW274150 and GW273629 were ineffective in treating migraine attacks in one placebo-controlled study $(n=126)$ [85] and in an open-label pharmacokinetic study [86]. Additionally, GW274150 was ineffective in a double-blind, placebocontrolled study as a prophylactic agent for migraine $(n=430)$ [87]. Since other NOS isoforms (nNOS and eNOS) may be involved in the effect of NO [88], the $\mathrm{CT}_{\mathrm{f}}(a)$ is 0.25 .

NO is most likely involved in the pathophysiology of migraine with a verisimilitude of +0.75 .

Is neurogenic inflammation (NI) involved in the headache aspect of migraine?

If dural NI is involved in migraine, as proposed by Markowitz et al. [89], NI inhibitors would be predicted to be effective in migraine. This is true to some extent because ergot alkaloids and triptan inhibit NI [90, 91]. These drugs are, however, not specific NI inhibitors [92, 93]; however, endothelin and NK-1 receptor antagonists effectively inhibit NI in animal studies [94, 95]. The $\mathrm{CT}_{\mathrm{v}}(a)$ is 0.5 .

Alternatively, several randomized clinical trials show no effect of substance P, neurokinin-1 antagonists [96-98], neurosteroid ganaxolone [99], endothelin antagonists [100], or the specific NI blockers CP122,288 and 4991w93 $[101,102]$ in the acute treatment of migraine. $\operatorname{The~}_{\mathrm{C}}(a)$ is 1.0 .

Since specific NI inhibitors have no effect in migraine, it is difficult to find a pivotal role for dural NI in migraine $[7,63]$ and the verisimilitude is -0.5 .

Is aura common in cluster headache attacks?

The next subject is theoretically important. If aura is not only linked to migraine with aura, but also with other primary headaches, such as cluster headaches, aura and migraine could be caused by two different mechanisms [57, 103]. In a recent paper [104], aura was described as being common in cluster headaches, with $23 \%$ of cluster headache patients in the study experiencing aura. Similarly, aura was reported in $28 \%$ of cluster headache patients in a series of 76 patients [105]. In two earlier studies, aura was reported in 4 [106] and 13\% [103], respectively, of cluster headache patients. In 1972, Graham mentioned that brief episodes of scintillating rarely, but occasionally occur before cluster headache attacks [107]. The $\operatorname{CT}_{\mathrm{v}}(a)$ for aura being common in cluster headache is thus 0.5 .

Dr. Karl Ekbom from Stockholm, Sweden, an expert in cluster headache [108, 109] and migraine with aura [110], was asked his opinion. In a series of 554 cluster headache 
patients, there were no cases of aura in connection with cluster headache attacks [111]. The $\mathrm{CT}_{\mathrm{f}}(a)$ is 1.0.

Aura is, therefore, likely to be rare in cluster headache patients, and the verisimilitude is -0.5 .

Hypothalamic activation is specific for cluster headache and other trigeminal autonomic cephalalgias

Functional PET imaging shed light on the genesis of migraine and cluster headache by repeatedly documenting activation in the midbrain and pons during migraine, and in the hypothalamus during cluster headache. Two PET investigations found activation in the posterior hypothalamus during nitroglycerin-induced cluster headache attacks [112, 113]. Voxel-based morphometry with MRI found changes in the same region [114]. Furthermore, with ${ }^{1} \mathrm{H}-\mathrm{MR}$ spectroscopy, hypothalamic- $N$-acetyl aspartate/ creatinine was reduced in patients with cluster headache versus controls [115]. In two patients with SUNCT, hypothalamic activation was observed with functional MRI $[116,117]$. In paroxysmal hemicrania, hypothalamic activation was found with PET [118]. In hemicrania continua, with a phenotype in between cluster headache and migraine, activation was observed both in the hypothalamus and in the brain stem [119].

In migraine without aura, hypothalamic activation was not found in two PET studies $(n=33)$ [4, 33]. Hypothalamic activation concurrent with brain stem activation was observed in one PET study in migraine without aura attacks $(n=7)$ [34, 73]. These activations persisted after successful treatment with sumatriptan [34, 73].

In this case, the Popper falsification rule [8] seems appropriate. Hypothalamic activation is not specific to cluster headache because it was observed in migraine without aura in a study with appropriate PET techniques [34].

\section{Discussion}

Current migraine-mechanism theories vary from the notion that the migraine attack "consists of an abnormal perception of otherwise normal circumstances, such as pain without evidence of primary nociceptive activation" [7] to "migraine may be a local manifestation of a systematic vascular abnormality rather than a primary cerebral phenomenon" [120] or to "migraine is a neurovascular disorder" [121].

Popper's verisimilitude calculation does not resolve problems always. Potentially, both the $\mathrm{CT}_{\mathrm{v}}(a)$ and $\mathrm{CT}_{\mathrm{f}}(a)$ can be 1.0 with a resulting verisimilitude of 0 . Sometimes, one must fall back to the Popper falsification method, where negative facts that can falsify the hypothesis are the main stay. Migraine data are often not validated well enough to allow clear-cut conclusions. Particularly, confirmatory studies using the same methodology are often lacking.

In areas like migraine research, which is often descriptive, many cases of contradictory data exist because of both biological variability per se and different methods of measuring the biological signal.

No grand unifying theory exists in migraine research that can be falsified by itself or by its predictions [8], leaving only isolated relevant problems of basic and clinical migraine research for testing.

When evaluating the problems, we often used a mixture of facts from both kinds of research. Verisimilitude determinations can supplement the usual pros and cons by forcing judgement of the evidence for hypothesis $a$ when assigning values to $\mathrm{CT}_{\mathrm{v}}(a)$ and $\mathrm{CT}_{\mathrm{f}}(a)$ [14]. According to Popper, $\operatorname{Vs}(a)$ calculation is an objective method for judging a scientific theory or the predictions derived from a theory [14].

Verisimilitude measures the best correspondence with facts and should not be confused with probability [14]. One can apply the simple verisimilitude formula to any field one knows well. Notably, verisimilitude calculations should not be applied to quantitative migraine treatment trials when a systematic review or meta-analysis is more appropriate [10-13].

Despite efforts at objectivity, some subjectivity remains in assigning values to $\mathrm{C}_{\mathrm{t}}(a)$ and $\mathrm{C}_{\mathrm{t}} \mathrm{f}(a)$. Some may disagree with my calculations, but anyone can easily assign alternative $\mathrm{C}_{\mathrm{t}}(a)$ and $\mathrm{C}_{\mathrm{f}}(a)$ values and calculate verisimilitude for themselves.

Among the 10 cases judged by verisimilitude calculations, there were two -0.5 (unlikely), four 0 (undecided), one +0.25 (probably likely), one +0.5 (likely), and one +0.75 (most likely) (Table 1). For one item, the falsification ad modum Popper [8] was found to be more suitable. There was no -1.0 (very unlikely), probably because there is always some historical or recent evidence for the hypothesis tested [89-91, 104, 105]. The -0.5 depend on the formulation of the question. In four cases, we could not decide whether the theory was true or false because the evidence for and against it was of equal weight.

The verisimilitude approach is not problem-free. To illustrate, I discuss two problems in detail: migraine as a pure CNS disorder, possible aura in cluster headache, and cortical spreading depression (CSD).

The theory that migraine is a dysfunction of the sensory modulatory network [7] can be re-formulated as migraine is a pure human brain disease. Many good arguments exist for both sides and the $\mathrm{CT}_{\mathrm{v}}(a)$ and $\mathrm{CT}_{\mathrm{f}}(a)$ will still be 1.0 with the facts used in my analysis (Table 1), and verisimilitude will be 0 . However, when using my prerogative as 
author and using our "natural instincts" (see vignette) combined with Popper's falsification theory [8], I believe that the verisimilitude should be negative.

Thus, the theory that migraine is a brain disease would predict that there is no non-brain disorder associated with it. The main falsifying argument of this prediction is the cardiovascular comorbidity associated with migraine [56]. For example, there is an association between cervical arterial dissection and migraine, mainly migraine with aura $[52,53]$. Additionally, migraine, particularly migraine with aura, is a risk factor for ischemic stroke [47, 56]. The arteries of the systemic circulation were also investigated [56, 120, 122]. Migraineurs with recent onset ( $<6$ years) had decreased brachial arterial diameters and compliances [56]. Decreased flow-mediated dilatation of the brachial artery was also found in two other studies in migraineurs $[120,122]$.

Furthermore, some genetic arteriopathies are associated with migraine [123, 124] and in CADASIL, where the notch-3 gene appears to be expressed exclusively in vascular smooth muscles within adult brain [125]. rCBF changes during migraine were similar in one case to migraine with aura $[6,126]$.

Circulating endothelial progenitor cell numbers and functions (i.e. endothelial repair markers) [127], are reduced, especially in migraine with aura patients [128]. In two studies [48, 129], the von Willebrand factor, a plasma marker of endothelial dysfunction, was increased in migraine. Thus, there is good evidence that migraine is associated with endothelial dysfunction, and could be the underlying link between migraine and cardiovascular risk $[49,128]$.

I believe that the arguments against the predictions of the neuronal theory of migraine falsify this theory [7]. Migraine is unlikely to be a brain-only disease. Another argument against the neuronal theory is that no other part of the human body experiences pain without nociceptive input except thalamic pain and other neuronal lesions with sensory signs [130]. In migraine, there can be allodynia, but no sensory signs [130]. I believe that, in addition to a clear CNS component, there is also a peripheral component in the headache phase. Regarding the source of pain, Goadsby recently stated "The pain process is likely to be a combination of direct factors, i.e. activation of the nociceptors of pain-producing intracranial structures, in concert with a reduction in the normal functioning of the endogenous pain control pathways that normally gate that pain" [7]. I agree that there is both a peripheral and central aspect of migraine headache. Because of the pulsating pain in migraine, I believe vascular nociception most likely [131] even though the verisimilitude of large arterial vasodilation during migraine was zero.
The question of aura in cluster headache

Four recent papers report prevalences of 4 to $28 \%$ for aura in cluster headache [103-106]. One may wonder how such a frequent and characteristic phenomenon went unrecognized by Baylor Horton, who described histaminic cephalalgia in $1938(n=181)$ [131]. Horton later in 1956 reported seeing 1,176 patients (1,023 men and 153 women) with histaminic cephalalgia [133]. Aura is not mentioned by Kudrow whose book from 1980 included 495 patients [132]. However, the cluster headache expert John R. Graham wrote "Now to our surprise we were able to establish that in 20 cluster headache patients brief episodes of scintillating scotoma rarely, but occasionally, did precede the cluster headache attacks" [107]. However, there are inconsistencies in the prevalences reported. The highest reported prevalence is $28 \%(n=76)$ [105] and the lowest is $4 \%(n=101)$ [107], a difference of $24 \%$ (95\% CI $13-$ $34 \%, P<0.0001$, Fisher's exact test). The difference between the 23 [104] and 4\% [106] prevalence is $19 \%$ (95\% CI $13-26 \%, P<0.0001)$. Also, prevalence was significantly different between the two largest studies: 23 $(n=246)$ [104] versus $13 \%(n=230)$ [103], a difference of $10 \%$ (95\% CI $2-16 \%, P=0.01)$. These differences demonstrate that the method of registering "so-called aura" must have varied considerably.

In contrast, no reports of aura in cluster headache were reported in a large series of 554 cluster headache patients from one Swedish center [111]. Karl Ekbom, who has a special interest in aura [110], personally interviewed 427 patients, and observed and questioned about 100 of them during spontaneous or provoked cluster headache attacks [111].

Confronted with these incomparable data, it is a matter of belief or trust. Both sets of contradictory data cannot be an approximation of the truth and I calculated the verisimilitude to be -0.5 . In my opinion, aura must be rare among cluster headache patients.

In conclusion, I believe verisimilitude calculations are suitable for many migraine and cluster headache mechanism problems. Contradictory data concerning a specific problem are common and a verisimilitude calculation enforces a qualitative judgement of the data. Sometimes, the resulting verisimilitude is zero, but both, $\mathrm{CT}_{\mathrm{v}}(a)$ and $\mathrm{CT}_{\mathrm{f}}(a)$, cannot be an approximation of the truth. In some cases, further investigation is needed or a clearer hypothesis should be formulated, and appropriate investigations aimed at falsifying the thesis [8] should be performed. Finally, positive evidence is never conclusive; but neither is negative evidence, nor would it be a good idea to pretend that it was [1].

Conflict of interest None. 


\section{References}

1. Lipton P (2005) The Medawar Lecture 2004 the truth about science. Philos Trans R Soc Lond B Biol Sci 360:1259-1269

2. Thomsen LL, Kruuse C, Iversen HK, Olesen J (1994) A nitric oxide donor (nitroglycerin) induces genuine migraine attacks. Eur J Neurol 1:73-80

3. Olesen J (2008) The role of nitric oxide (NO) in migraine, tension-type headache and cluster headache. Pharmacol Ther 120:157-171

4. Afridi SK, Matharu MS, Lee L, Kaube H, Friston KJ, Frackowick RS et al (2005) A PET study exploring the laterality of brainstem activation in migraine using glyceryl trinitrate. Brain 128:932-939

5. Lassen LH, Haderslev PA, Jacobsen VB, Iversen HK, Sperling $\mathrm{B}$, Olesen J (2002) CGRP may play a causative role in migraine. Cephalalgia 22:54-61

6. Olesen J, Iversen HK, Thomsen LL (1993) Nitric oxide supersensitivity: a possible molecular mechanism of migraine pain. Neuroreport 4:1027-1030

7. Goadsby PJ, Charbit AR, Andreou AP, Akerman S, Holland PR (2009) Neurobiology of migraine. Neuroscience 161:327-341

8. Popper KR (1959) The logic of scientific discovery. Routledge, London

9. International Headache Society Clinical Trial Subcommittee (2000) Guidelines for controlled trials of drugs in migraine, vol 20, 2nd edn. Cephalalgia, pp 765-786

10. Tfelt-Hansen P, De Vries P, Saxena PR (2000) Triptans in migraine. A comparative review of pharmacology, pharmacokinetics and efficacy. Drugs 60:1259-1287

11. Ferrari MD, Roon KI, Lipton RB, Goadsby PJ (2001) Oral triptans (serotonin 5-HT1B/1B agonists) in acute migraine treatment: a meta-analysis of 53 trials. Lancet 358:1668-1675

12. Linde K, Rossnagel K (2004) Propranolol for migraine prophylaxis. Cochrane Database Syst Rev 2:CD003225

13. Sultan A, McQuay HJ, Moore RA, Derry S (2009) Single dose oral flurbiprofen for acute postoperative pain in adults. Cochrane Database Syst Rev (3):CD007358

14. Popper KR (2003) Conjectures and refutations. The growth of scientific knowledge. Routledge, London

15. Graham JR, Wolff HG (1938) Mechanism of migraine headache and action of ergotamine tartrate. Arch Neurol Psychiatry 39:737-763

16. Wolff HG (1963) Headache and other head pain, 2nd edn. Oxford University Press, New York

17. Friberg L, Olesen J, Iversen HK, Sperling B (1991) Migraine pain associated with middle cerebral dilatation: reversal by sumatriptan. Lancet 336:13-17

18. Thomsen LL, Iversen HK, Olesen J (1995) Cerebral blood flow velocities are reduced during attacks of unilateral migraine without aura. Cephalalgia 15:109-116

19. Totaro R, De matteis G, Marini C, Balassarre M, Carolei A (1997) Sumatriptan and cerebral blood flow velocity changes during migraine attacks. Headache 37:635-639

20. Zwetsloot CP, Caebeke J, Odink J, Ferrari MD (1991) Vascular reactivity during migraine attacks: a transcranial Doppler study. Headache 31:593-595

21. Zwetsloot CP, Caebeke J, Ferrari MD (1993) Lack of asymmetry of middle cerebral artery blood velocities in unilateral migraine. Stroke 24:1335-1338

22. Schoonman GG, van der Grond J, Kortman C, van der Geest RJ, Terwindt GM, Ferrari MD (2008) Migraine headache is no associated with cerebral or meningeal vasodilation-a 3T magnetic resonance angiographic study. Brain 131:2192-2200
23. Goadsby PJ, Edvinsson L, Ekman R (1990) Vasoactive peptide release in the extracerebral circulation of humans during migraine headache. Ann Neurol 28:183-187

24. Goadsby PJ, Edvinsson L (1993) The trigeminovascular system and migraine: studies characterizing cerebrovascular and neuropeptide changes seen in humans and in cats. Ann Neurol 33:48-56

25. Vause CV, Durham PL (2009) Calcitonin gene-related peptide differentially regulates gene and protein expression in trigeminal neurons and glia cells: findings from array analysis. Cephalalgia 29(suppl 1):116-117

26. Tvedskov JF, Lipka K, Ashina M, Iversen HK, Schifter S, Olesen J (2005) No increase of calcitonin gene-related peptide in jugular blood during migraine. Ann Neurol 58:561-563

27. Tfelt-Hansen P (2010) Calcitonin gene-related peptide in external jugular vein during migraine and cluster headache. Is it increased? In: Olesen J (ed) Role of calcitonin gene-related peptide (CGRP) and adrenomedullin (AM) in migraine. Frontiers in headache research, vol 17. Oxford University Press (in press)

28. Kelman L (2004) The premonitory symptoms (prodrome): a tertiary care study of 893 migraineurs. Headache 44:865-872

29. Olesen J, Goadsby PJ, Ramadan N, Tfelt-Hansen P, Welch KMA (eds) (2006) The headaches, 3rd edn. Lippincott Williams and Wilkins, Philadelphia, pp 1-1169

30. Olesen J, Larsen B, Lauritzen M (1981) Focal hyperemia followed by spreading oligemia and impaired activation of $\mathrm{rCBF}$ in classic migraine. Ann Neurol 9:344-352

31. Lauritzen M, Olsen TS, Lassen NA, Paulson OB (1983) Changes in regional cerebral blood flow during the course of classic migraine attacks. Ann Neurol 13:633-641

32. Hajdikhani N, Sanchez del Rio M, Wu O, Schwartz D, Bakker D, Fischl B et al (2001) Mechanisms of migraine aura revealed by functional MRI in human visual cortex. Proc Natl Acad Sci USA 08:4687-4692

33. Weiller C, May A, Limroth V, Jüpter M, Kaube H, Schayck RV et al (1995) Brain stem activation in spontaneous human migraine attacks. Nat Med 1:658-660

34. Denuelle M, Fabre N, Payoux P, Chollet F, Geraud G (2007) Hypothalamic activation in spontaneous migraine attacks. Headache 47:1418-1425

35. Haas DC, Kent PF, Friedman DI (1993) Headache caused by a single lesion of multiple sclerosis in the periaqueductal gray area. Headache 33:452-455

36. Afridi S, Goadsby PJ (2003) New onset of migraine with a brain stem cavernoma. J Neurol Neurosurg Psychiatry 74:680-682

37. SchoenenJ Maetens, de Noordhout A, Timsit-Berthier M, Timsit M (1986) Contingent negative variation and efficacy of betablocking agents in migraine. Cephalalgia 6:229-233

38. Ayata C, Jin H, Kudo C, Dalkara T, Moskowitz MA (2006) Suppression of cortical depression in migraine prophylaxis. Ann Neurol 59:652-661

39. Storer RJ, Goadsby PJ (1997) Microiontophoretic application of serotonin (5HT) 1B/1D agonists inhibits trigeminal cell firing in the cat. Brain 120:2171-2177

40. Storer RJ, Goadsby PJ (2004) Topiramate inhibits trigeminovascular neurons in the cat. Cephalalgia 24:1049-1056

41. Kaube H, Hoskin KL, Goadsby PJ (1993) Inhibition by sumatriptan of central trigeminal neurons only after blood-brain barrier disruption. Br J Pharmacol 109:788-792

42. Hoskin KL, Bulmer DC, Goadsby PJ (1999) Fos expression in the trigeminocervical complex of the cat after stimulation of the superior sagittal sinus is reduced by L-NAME. Neurosci Lett 266:173-176 
43. Goadsby PJ, Hoskin KL (1999) Differential effects of low dose CP122, 288 and eletriptan on fos expression due to stimulation of the superior sagittal sinus in cat. Pain 82:15-22

44. Bolay H, Reuter U, Dunn AK, Huang Z, Boas DA, Moskowitz MA (2002) Intrinsic brain activity triggers trigeminal afferents in a migraine model. Nat Med 8:136-142

45. Maneesri S, Patamanon J, Patumja S, Srkiatknachora A (2004) Cortical spreading depression, meningeal inflammation and trigeminal nociception. Neuroreport 15:1623-1637

46. Drummond PD, Lance JW (1983) Extracranial vascular changes and the source of pain in migraine headache. Ann Neurol 13:3237

47. Bousser M-G, Welch KMA (2005) Relation between migraine and stroke. Lancet Neurol 4:533-542

48. Tietjen GE (2009) Migraine a systemic vasculopathy. Cephalalgia 29:987-996

49. Stam AH, Haan J, van den Maagdenberg AMJM, Ferrari MD, Terwindt GM (2009) Migraine and genetic and acquired vasculopathies. Cephalalgia 29:1006-1017

50. Bigal ME, Santanello NC, Buse DC, Kurth T, Golden WM, Robbins MS, Lipton RB (2009) Migraine with and without aura are associated with cardiovascular disease. The American migraine prevalence and prevention study. Cephalalgia 29(Suppl 1):8

51. Artto VA, Meyso TM, Metso AJ, Putaala J, Haapaniemi E, Färkkilä M et al (2009) Migraine with aura is a risk factor for cervical artery dissection; a case control study. Cephalalgia 29(Suppl 1):114

52. Rubenstein SM, Peerdeman SM, van Tulder MW, Riphagen I, Haldeman S (2005) A systematic review of the risk factors for cervical artery dissection. Stroke 36:1575-1580

53. Tzourio C, Benslamia L, Guillon B, Aïdi S, Bertrand M, Berthet $\mathrm{K}$ et al (2002) Migraine and the risk of cervical arterial dissection: a case-controlled study. Neurology 59:435-437

54. Tfelt-Hansen P, Le H (2009) Calcitonin gene-related peptide in blood: is it increased in the external jugular vein during migraine and cluster headache attacks? A review. J Headache Pain 10:137-143

55. Kruit MC, Launer LJ, Ferrari MD, van Buchem MA (2005) Infarcts in the posterior circulation territory in migraine. The population-based MRI CAMERA study. Brain 128:2068-2077

56. Vanmolkot FH, Van Bortel LM, de Hoon JN (2007) Altered arterial function in migraine of recent onset. Neurology 68:1563-1570

57. Goadsby PJ (2001) Migraine, aura, and cortical spreading depression: why are we still talking about it? Ann Neurol 49:4-6

58. Olesen J, Friberg L, Olsen TS, Iversen HK, Lassen NA, Andersen AR et al (1990) Timing and topography of cerebral blood flow, aura and headache during migraine attacks. Ann Neurol 28:791-798

59. Moskowitz MA, Nozahi K, Kraig RP (1993) Neocortical spreading depression provokes the expression of c-fos proteinlike immunoreactivity within trigeminal nucleus caudalis via trigeminovascular mechanisms. J Neurosci 13:1167-1177

60. Read SJ, Hirst WD, Upton N, Parsons A (2001) Cortical spreading depression produces increased cGMP levels in cortex and brain stem that is inhibited by tonabersat (SB-220453) but not sumatriptan. Brain Res 891:69-77

61. Kunkler PE, Kraig RP (2003) Hippocampal spreading depression bilaterally activates the caudal trigeminal nucleus in rodents. Hippocampus 13:835-844

62. Gursoy-Ozdemir Y, Qui J, Matsuoka N, Bolay H, Bernpohl D, Jin $\mathrm{H}$ et al (2004) Cortical spreading depression activates and upregulates MMP-9. J Clin Invest 113:1447-1455

63. Messlinger K (2009) Migraine; where and how does the pain originate? Exp Brain Res 196:179-193
64. Russell MB, Olesen J (1996) A nosographic analysis of migraine aura in a general population. Brain 119:335-361

65. Hauge AW, Asghar MS, Schytz HW, Christensen K, Olesen J (2009) Effects of tonabersat on migraine with aura; a randomised, double-blind, placebo-controlled crossover study. Lancet Neurol 8:723-728

66. Ebersberger A, Schaible HG, Averbech B, Richter F (2001) Is there a correlation between spreading depression, neurogenic inflammation, and nociception that might cause migraine headache? Ann Neurol 49:7-13

67. Ingvardsen BK, Lauersen H, Olsen UB, Hansen AJ (1997) Possible mechanism of $\mathrm{c}$-fos expression in the trigeminal nucleus caudalis following cortical spreading depression Pain 72:407-415

68. Olesen J, Tfelt-Hansen P, Henriksen L, Larsen B (1981) Common migraine may not be initiated by cerebral ischemia. Lancet II: $438-440$

69. Sanchez del Rio M, Bakker D, Wu O, Agosti R, Mitsikostas PD, Ostergaard L et al (1999) Perfusion weighted imaging during migraine: spontaneous visual aura and headache. Cephalalgia 19:701-707

70. De Benedittis G, Ferrari Da Passano C, Granata G, Lorenzetti A (1999) CBF changes during headache-free periods and spontaneous/induced attacks in migraine with and without aura: a TCD and SPECT comparison study. J Neurosurg Sci 43:141-146

71. Andersson JL, Muhr C, Liljen A, Valind S, Lundberg PÅ, Långström B (1997) Regional cerebral blood flow and oxygen metabolism during migraine with and without aura. Cephalalgia 27:570-579

72. Bednarczyk EM, Remler B, Weikart C, Nelson AD, Reed RC (1998) Global cerebral blood flow, blood volume, and oxygen metabolism in patients with migraine headache. Neurology 50:1736-1740

73. Denuelle M, Fabre N, Payoux P, Chollet F, Geraud G (2008) Posterior cerebral hypoperfusion in migraine without aura. Cephalalgia 28:856-862

74. Woods RP, Iacoboni M, Mazziotta JC (1994) Brief report: bilateral spreading hypoperfusion during spontaneous migraine headache. N Eng J Med 331:1689-1692

75. Peters GA (1953) Migraine: diagnosis and treatment with emphasis on the migraine-tension headache, provocative tests and use of rectal suppositories. Proc Staff Meet Mayo Clin 28:673-686

76. Sicuteri F, del Bene ED, Poggioni M, Bonnazzi A (1987) Unmasking latent dysnociception in healthy subjects. Headache 27:180-185

77. Tfelt-Hansen P, Daugaard D, Lassen LH, Iversen HK, Olesen J (2009) Prednisolone reduces nitric oxide-induced migraine. Eur J Neurol 16:1106-1111

78. Thomsen LL, Iversen HK, Brinck TA, Olesen J (1993) Arterial supersensitivity to nitric oxide (nitroglycerin) in migraine sufferers. Cephalalgia 13:395-399

79. Juhasz G, Zsombok T, Modos EA, Olajos S, Jakab B, Nemeth J et al (2003) NO-induced migraine attacks: strong increase in plasma calcitonin gene-related peptide (CGRP) concentration and negative correlation with platelet serotonin release. Pain 106:461-470

80. Juhasz G, Zsombok T, Jakab B, Nemeth J, Szoksanyl J, Bagny $\mathrm{G}$ (2005) Sumatriptan causes parallel decrease in plasma calcitonin gene-related peptide (CGRP) concentration and migraine headache during nitroglycerin induced migraine attacks. Cephalalgia 25:179-183

81. Juhasz G, Zsombok T, Gonda X, Nagyne N, Modosne E, Bagdy $G$ (2007) Effects of autogenic training on nitroglycerin-induced headache. Headache 47:371-383

82. Christiansen I, Thomsen LL, Daugaard D, Ulrich V, Olesen J (1999) Glyceryl trinitrate induces attacks of migraine without aura in sufferers of migraine with aura. Cephalalgia 19:660-667 
83. Christiansen I, Daugaard D, Lykke Thomsen L, Olesen J (2000) Glyceryl trinitrate induced headache in migraineurs-relation to attack frequency. Eur J Neurol 7:405-411

84. Lassen LH, Ashina M, Christiansen I, Ulrich V, Grover R, Donaldson J et al (1998) Nitric oxide synthase inhibition: a new principle in the treatment of migraine attacks. Cephalalgia 18:27-32

85. Palmer JE, Guillard FL, Laurijssens BE, Wentz AL, Dixon RM, Williams PM (2010) A randomised, single-blind, placebo-controlled, adaptive clinical trial of GW274150, a selective iNOS inhibitor, in the treatment of acute migraine. Cephalalgia (in press)

86. Van der Schueren BJ, Lunnon MW, Laurijssens BE, Guillard F, Palmer J, Van Hecken A et al (2009) Does the unfavorable pharmacokinetic and pharmacodynamic profile of the iNOS inhibitor GW273629 lead to inefficacy in migraine? J Clin Pharmacol 49:281-290

87. Hoye K, Laurijssens BE, Harnisch LO, Twormey CK, Dixon RM, Kirkham A et al (2009) Efficacy and tolerability of the iNOS inhibitor GW274150 administered up to $120 \mathrm{mg}$ daily for twelve weeks in the prophylactic treatment of migraine. Cephahalgia 29:132

88. Akerman S, Williamson DJ, Kaube H, Goadsby PJ (2002) Nitric oxide synthase inhibitors can antagonize neurogenic and calcitonin gene-related peptide induced dilation of dural meningeal vessels. Br J Pharmacol 130:62-68

89. Markowitz S, Saito K, Moskowitz MA (1987) Neurogenically mediated leakage of plasma protein occurs from blood vessels in the dura mater but not brain. J Neurosci 7:4129-4136

90. Saito K, Markowitz S, Moskowitz MA (1988) Ergot alkaloids block neurogenic extravasation in dura mater: proposed action in vascular headaches. Ann Neurol 24:732-737

91. Buzzi MG, Mokowitz MA (1991) Evidence for the 5-HT1B/1D receptors mediating the antimigraine effect of sumatriptan and dihydroergotamine. Cephalalgia 11:165-168

92. Tfelt-Hansen P, Saxena PR (2006) Ergot alkaloids in the acute treatment of migraine. In: Olesen J, Goadsby PJ, Ramadan NM, Tfelt-Hansen P, Welch KMA (eds) The Headaches, 3rd edn. Lippincott Williams \& Wilkins, Philadelphia, pp 459-467

93. Saxena PR, Tfelt-Hansen P (2006) Triptans, 5HT1B/1D agonists in the acute treatment of migraine. In: Olesen J, Goadsby PJ, Ramadan NM, Tfelt-Hansen P, Welch KMA (eds) The Headaches, 3rd edn. Lippincott Williams \& Wilkins, Philadelphia, pp 469-503

94. Brändli P, Löffler BM, Breu V, Osterwalder R, Maire JP, Clozel M (1996) Role of endothelin in mediating neurogenic plasma extravasation in rat dura mater. Pain 64:315-322

95. Phebus LA, Johnson KW, Stengel PW, Lobb KL, Nixon JA, Hipskind PA (1997) The non-peptide NK-1 receptor antagonists LY303870 inhibits neurogenic dural inflammation in guinea pigs. Life Sci 60:1553-1561

96. Connor HE, Bertin L, Gilles S, Beattie DT, Ward P, the GR295171 Clinical Study Group (1998) Clinical evaluation of a novel, potent, CNS penetrating $\mathrm{NK}_{1}$ receptor antagonist in the acute treatment of migraine. Cephalalgia 18:392

97. Diener HC (2003) RPR100893, a substande-P antagonist, is not effective in the treatment of migraine attacks. Cephalalgia 23:183-185

98. Goldstein DJ, Wang O, Saper JR, Stoltz R, Silberstein SD, Mathew NT (1997) Ineffectiveness of neurokinin-1 antagonist in acute treatment of migraine: a crossover study. Cephalalgia 17:785-790

99. Data J, Britch K, Westergaard N, Weihnuller F, Harris S, Swarz H, Silberstein S, Goldstein J, Ryan R, Saper J, Londborg P, Winner P, Klapper J (1998) A double-blind study of ganaxolone in the treatment of migraine headaches with and without aura in premenopausal females. Headache 38:380

100. May A, Gijsman HJ, Wallnoefer A, Jones R, Diener HC, Ferrari MD (1996) Endothelin antagonist bosentan blocks neurogenic inflammation, but is not effective in aborting migraine attacks. Pain 67:375-378

101. Roon K, Diener HC, Ellis P, Hettiarachchi J, Poole P, Christiansen I, Ferrari MD, Olesen J (1997) CP-122, 288 blocks neurogenic inflammation, but is not effective in aborting migraine attacks: results of two controlled clinical studies. Cephalalgia 17:245

102. Earl NL, McDonald SA, Lowy Mt, 4991 W93 Investigator Group (1999) Efficacy and tolerability of the neurogenic inflammation inhibitor, 4991W93, in the acute treatment of migraine. Cephalalgia 19:357

103. Bahra A, May A, Goadsby PJ (2002) Cluster headache: a prospective clinical study with diagnostic implications. Neurology $58: 354-361$

104. Schürks M, Kurth T, de Jesus J, Jonsic M, Rosskopf D, Diener HC (2006) Cluster headache: medical presentation, lifestyle factors, and medical treatment. Headache 46:1246-1254

105. Wöber C, Knopf A (2009) Migrainous features in cluster headache. Cephalalgia 29(suppl 1):44 Abstract

106. Silberstein SD, Niknam R, Rozen TD, Young WB (2000) Cluster headache with aura. Neurology 54:219-221

107. Graham JR (1972) Cluster headache. Headache 11:175-185

108. Ekbom K, Svensson DA, Träff H, Waldenlind E (2002) Age at onset and sex ratio in cluster headache: observation over three decades. Cephalalgia 22:94-100

109. Ekbom K, Svensson DA, Pedersen NL, Waldenlind E (2006) Life time prevalence and concordance risk of cluster headache in the Swedish twin population. Neurology 67:798-803

110. Ekbom K (1970) A clinical comparison of cluster headache and migraine. Acta Neurol Scand 46(Suppl 41):1-48

111. Ekbom K, Waldenlind E, Tfelt-Hansen P (2009) Cluster headache and aura. Headache 49:786-787

112. May A, Bahra A, Buchel C, Frackowiak RS, Goadsby PJ (1998) Hypothalamic activation in cluster headache. Lancet 352:275-278

113. May A, Bahra A, Büchel C, Frackowiak RS, Goadsby PJ (2000) PET and MRA findings in cluster headache and MRA in experimental pain. Neurology 55:1328-1335

114. May A, Ashenburner J, Büchel C, McGonicle DJ, Friston KJ, Frackowiak RS et al (1999) Correlation between structural and functional changes in brain in an idiopathic headache syndrome. Nat Med 5:836-838

115. Lodi R, Oieranggeli G, Tonon C, Cevoli S, Testa C, Bivona G et al (2006) Study of hypothalamic metabolism in cluster headache by proton MR spectroscopy. Neurology 66:1264-1266

116. May A, Bahra A, Büchel C, Turner R, Goadsby PJ (1999) Functional magnetic resonance imaging in spontaneous attacks of SUNCT: short-lasting unilateral neuralgiform headache with conjunctival injection and tearing. Ann Neurol 46:791794

117. Matharu MS, Cohen AS, Boes CJ, Goadsby PJ (2003) Shortlasting unilateral neuralgiform headache with conjunctival injection and tearing syndrome: a review. Curr Pain Headache Rep 7:308-318

118. Matharu MS, Cohen AS, Frackowiak RS, Goadsby PJ (2006) Posterior hypothalamic activation in paroxysmal hemicrania. Ann Neurol 59:535-545

119. Matharu MS, Cohen AS, MGGonigle DJ, Ward N, Frackowiak RS, Goadsby PJ (2004) Posterior hypothalamic and brainstem activation in hemicrania continua. Headache 44:747-761

120. Yetkin E, Ozisik H, Ozcan C, Aksoy Y, Turban H (2007) increased dilator response to nitrate and decreased flow-mediated dilatation in migraineurs. Headache 47:104-110 
121. Villalon CM, Olesen J (2009) The role of CGRP in the pathophysiology of migraine and efficacy of CGRP receptor antagonists as acute antimigraine drugs. Pharmacol Ther 124:309-323

122. Yetkin E, Ozisik H, Ozcan C, Aksoy Y, Turban H (2006) Decreased endothelium-dependent vasodilatation in patients with migraine: a new aspect to vascular pathophysiology of migraine. Coron Artery Dis 17:29-33

123. Chabriat H, Joutel A, Dichgans M, Tournier-Lasserve E, Bousser M-G (2009) CADASIL. Lancet Neurol 643-653

124. Dichgans M, Mayer M, Uttner I, Brüning R, Müller-Höcker J, Rungger G et al (1998) The phenotypic spectrum of CADASIL: clinical findings in 102 cases. Ann Neurol 44:731-739

125. Moskowitz MA, Kurth T (2007) Blood vessels, migraine, and stroke. Stroke 38:3117-3118

126. Tfelt-Hansen P, Olesen J (2008) Delayed hyperperfusion following migraine with a prolonged aphasic aura in a patient with CADASIL. Cephalalgia 28:899-902

127. Schwedt JJ (2009) Endothelial dysfunction in migraine. Cephalalgia 997-1002
128. Lee ST, Chu K, Jung KM, Kim DH, Choe VN, Kim JH et al (2008) Decreased number of endothelial progenitor cells in patients with migraine. Neurology 70:1510-1517

129. Tiejten GE (2007) Migraine as a systemic disorder. Neurology 68:1555-1556

130. Olesen J, Burstein R, Ashina M, Tfelt-Hansen P (2009) Origin of pain (nociception) in migraine. Lancet Neurol 8:679-690

131. Horton BT, MacLean AR, WMcK Craig (1939) A new syndrome of vascular headache: results of treatment with histamine: preliminary report. Proc Staff Meet Mayo Clinic 14:257-260

132. Kudrow L (1980) Cluster headache. Mechanisms and management. Oxford University Press, New York

133. Horton BT (1956) Histaminic cephalalgia; differential diagnosis and treatment. Proc Staff Meet Mayo Clin 1:325-333

134. May A (2005) The role of imaging in the pathophysiology and diagnosis of headache. Current Opin Neurol 18:293-297 